\section{TURN YOUR VISION INTO REALITY}

Whether you know exactly what you want or are just looking for ideas to complete your new surgery design, you should visit A-dec at one of their four UK showrooms.

At the showroom you can test drive the complete spectrum of fully integrated, high quality dental chairs, innovative dental lights and ergonomic cabinetry solutions. After all, you could spend over 26,565 hours with your dental chair throughout your career so it needs to work for you and your dental team.

Also at the showroom you'll be introduced to the A-dec difference display which shows the various high quality A-dec parts that go into every chair. A-dec's design and engineering is often imitated but never duplicated. The difference is in the details.

To see for yourself what makes A-dec different visit one of the four UK showrooms or call 0800 233285 for more information. www.a-dec.co.uk

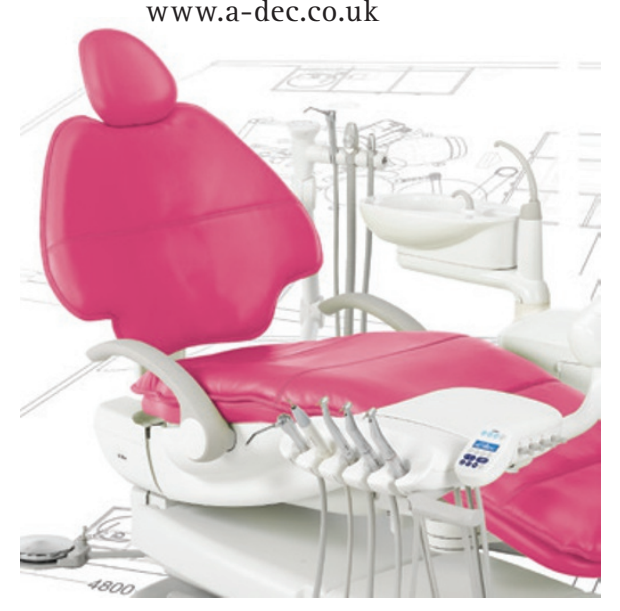

\title{
LET YOUR PRACTICE SOOTHE NERVOUS PATIENTS
}

Many people are still scared of the dentist, and it is often the reason given for patients not attending regular appointments. Make your practice a welcoming environment for everyone, by giving it a redesign with the help of Tavom UK.

Dental phobia often starts from a childhood association with unpleasant sights, sounds and smells of a surgery. Modern practices can be a much friendlier environment: by making use of space, colour and light, nervous patients can be soothed the minute they enter and feel confident that they are in safe and professional hands.

Tavom UK is an expert in practice redesign. With years of experience manufacturing bespoke cabinetry for the medical and dental industries, its team will help to design the perfect modern workspace. With beautiful cabinets and benches available in a range of colours and finishes, a practice refreshed by Tavom UK will keep any memories of gloomy and intimidating surgeries firmly in the past.

Tavom UK will project-manage your redesign from beginning to end, and provide on-going customer service that is second-tonone. Call today to find out more on 08707521121.

www.tavomuk.com

\section{A SLEEK AND STYLISH SURGERY}

There are many different areas to consider when planning your dental surgery, a fundamental question being: which dental unit should you use? The Skema 8 from Castellini is the ideal response.

The Skema 8 provides the complete treatment centre, offering integrated specialist instruments and exclusive technologies all within a beautifully crafted ergonomic framework. It comes with a host of multimedia options and accessories so you can demonstrate your commitment to providing the most up-to-date dental treatments to all your patients.

Chances are you will spend more time at your workplace than you will at home, so you should make sure that every aspect of your surgery makes you feel proud and reflects your identity. The Skema 8 allows you to do just this; with its sleek and stylish exterior it is available in a range of colours to suit you and your surgery.

The Skema 8 integrated package can be purchased with a five year warranty that includes the costs of all your service kits ensuring full compliance to CGQ regulations.

Become a part of Castellini's longstanding tradition today by making the Skema 8 the cornerstone of your surgery. Call 08000933975 and speak to Castellini UK Ltd directly for assistance.

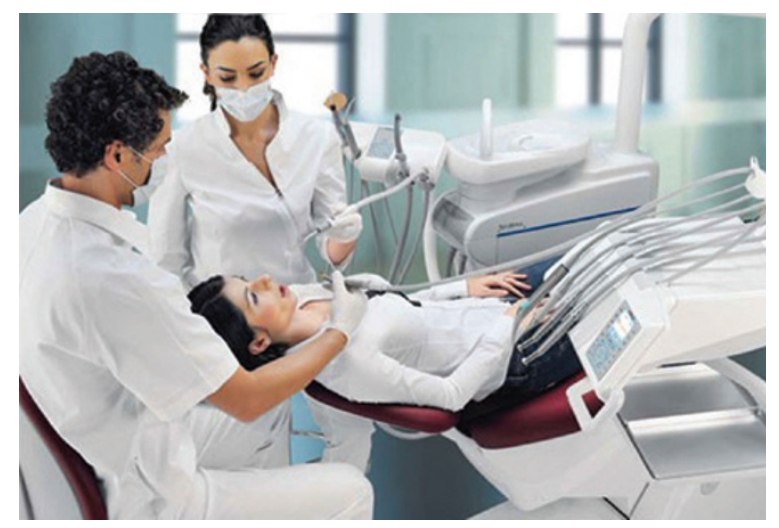

\section{A COMPLETE RANGE OF DECON SERVICES}

Dental Decontamination Ltd offer a complete range of services designed to give practices ultimate peace of mind.

In addition to supplying the complete Mocom range of autoclaves, Dental Decontamination offer a fast and reliable Repair Service designed to get you back up and running as quickly as possible. With a national team of Approved Autoclave Engineers, who specialise in autoclave repairs covering the majority of autoclave makes and models in the den- tal industry, Dental Decontamination aim to solve your problem and get you working again with a minimum of fuss and inconvenience. Simply call their hotline 01253736355 and an engineer will call you back under their Free Phone Repair Service. Wherever possible they will try to solve your problem over the phone to get you working again. If this is not possible they will arrange a visit and if they can't solve your problem in-house they will loan you an autoclave whilst yours is being repaired.

Dental Decontamination also offer an extremely cost-effective validation service for both vacuum and non-vacuum autoclaves at an extremely good price.

For further information call 01253736355 or visit www. dentaldecontamination.net. 